\title{
Qualitative and Quantitative Analysis of Some Brands of Valerian Pharmaceutical Products
}

\author{
Saeedeh Ghafari*, Somayeh Esmaeili, Hamedeh Aref, Farzaneh Naghibi and \\ Mahmoud Mosaddegh \\ Traditional Medicine and Materia Medica Research Center, Shaheed Beheshti University of \\ Medical Sciences, P.O.Box 14155-6354, Tehran, Iran \\ Telephone / Fax: +98 21 88776027, *E-mail: sghafari@itmrc.org
}

KEYWORDS HPLC (High Performance Liquid Chromatography). Valerenic Acid-Determination

\begin{abstract}
One of the important active compounds of valerian is valerenic acid, which is supposed to be the chemical factor responsible for the sedative effect of valerian. The aim of this work is identification and determination of valerenic acid in some brands of valerian pharmaceutical products including tablet, caplet, capsule, drop and comparison them. Following extraction by maceration method with methanol $80 \%$, thin layer chromatography (TLC) method was used to qualify the valerenic acid content of some brands of valerian pharmaceutical products using ethyl acetate- hexane- methanol $(0.5: 3: 7)$ as a mobile phase comparing to the authentic sample. Also high performance liquid chromatography (HPLC) method was used to quantify the valerenic acid content. The operating conditions were C- 18 reversed phase (VP-ODS-250 x $4.6 \mathrm{~mm}$ ) column, acetonitrile as mobile phase with constant flow rate of $0.8 \mathrm{ml} / \mathrm{min}$ and UV detection at $220 \mathrm{~nm}$. Valerenic acid amount in some brands of German valerian products (Futuran Baldrian tablet, Baldrian Hopfen tablet, Euvegal caplet) was $0.03-0.16 \%$ and in some of Iranian products (Neurogol tablet, Valerian capsule and Antimigrain Herbal drop) was 0.05-2.8\%. A rapid, simple and utilizable high performance liquid chromatography (HPLC) method was used for determination of valerenic acid in valerian products. All of the brands contain acceptable range of valerenic acid (not less than $0.04 \%$ ). The amount of valerenic acid according the suggested direction on the label of these products, in Iranian valerian products was less than German valerian products.
\end{abstract}

\section{INTRODUCTION}

Valerian (Valeriana officinalis) has been used in traditional medicine and traditional therapeutic such as to promote sleep, anxiolytic for nervous unrest, neuralgia, epilepsy, to relieve digestive and other spasms of smooth muscle. The valerian includes iridoids known as valepotriates, essential oil and non-volatile cyclopentane sesquiterpenes known as valerenic acid and derivatives (Mills and Bone 2000). It was considered to have a remarkable influence on the cerebrospinal system, inparticular as a sedative in conditions of nervous unrest, stress and neuralgia (USP 2000). Recently, attention has focused on valerenic acid and its derivatives as important sedative components unique to Valeriana officinalis. Powdered valerian contains not less than $0.3 \%$ of volatile oil and not less than $0.04 \%$ vale-

Corresponding Author:

Saeedeh Ghafari,

Traditional Medicine and Materia Medica Research

Center, Shaheed Beheshti University of Medical

Sciences, P.O.Box 14155-6354, Tehran, Iran

Telephone / Fax: +98 2188776027,

E-mail: sghafari@itmrc.org renic acid. Since the safety of the valepotriates has been questioned, until there is better information, the best choice is to use water-soluble extracts standardized for valerenic acid content (Pizzorno and Murray 1999).

Boyadzhiev et al. (Boyadzhiev et al. 2004) found that increased processing temperature favors extraction kinetics, but provokes moderate degradation of valerenic acids. Valerenic acid and derivatives concentrations were assayed by high performance liquid chromatography (HPLC) using a C18 KROMSSILE (200 X $4.6 \mathrm{~mm})$ column and a mobile phase containing methanol and an orthophophoric acid solution $0.5 \% \mathrm{v} / \mathrm{v}$ in water at ratio of 75: 25 at a constant flow rate of $1 \mathrm{ml} /$ min (Tarrado 2003). Thirty- one commercial valerian preparations available in Australia were analyzed by HPLC for valepotriates and valerenic acid and derivatives and the concentration of valerenic acid and its derivatives ranged from< 0.01 to $6.32 \mathrm{mg} / \mathrm{g}$ products (Shohet et al. 2001). Bokstaller, et al. published high performance liquid chromatography analysis using ODS2 $5 \mu \mathrm{m}$ (300x $2.5 \mathrm{~mm})$ and $30 \mathrm{~min}$ gradient elution with 
$6 \%$ acetonitrile with photodiode array detection and signal extraction at $221 \mathrm{~nm}$ for determination of valerenic acid (http://www. purecaps.com/ PDF/ QA/ VL 16.pdf).

In this work, some of brands of valerian pharmaceutical products were extracted by maceration method and valerenic acid was identified comparing with authentic sample by thin layer chromatography (TLC) method. High performance liquid chromatography (HPLC) was used for determination of valerenic acid in some of the valerian products.

\section{MATERIALS AND METHOD}

Chemical Preparation: Valerenic acid standard $(99.45 \%)$ was prepared from Analytik Co. Germany products (Futuran Baldrian tablet, Baldrian Hopfen tablet and Euvegal caplet) were prepared from Helal Ahmar pharmacy. Iranian products (Neurogol tablet, Valerian capsule, Antimigrain Herbal drop) were purchased from different pharmacies in Tehran. The high performance liquid chromatography (HPLC) system consisted of a pump (LC-10ADVP Shimadzu) and C-18 reversed-phase (VP- ODS-250 x 4.6mm) column. The column effluent was monitored with a variable wavelength UV detector at $220 \mathrm{~nm}$. The detector was connected to a computer and the data were analyzed by CLASS VP program.

All of the solvents were prepared from Darmstadt. Merck Co.

Sample Preparation: For analysis, four to six tablets, two caplets, three capsules were used. The samples weighted and transferred into a flask and the flasks filled with $(20-60 \mathrm{ml})$ methanol $80 \%$, shake and the supernatant was filtered through a $0.45 \mu \mathrm{m}$ filter. The extraction process was repeated two more times on the residue. 5 $\mathrm{ml}$ drop was diluted with $20 \mathrm{ml}$ methanol and then filtered by $0.45 \mu \mathrm{m}$ filter.

Sampling of Thin Layer Chromatography $(\boldsymbol{T L C})$ : Thin layer chromatography was performed in three solvent systems: toluene- ethyl acetate (75: 25), ethyl acetate- hexane- glacial acetic acid (65: 35: 0.5), ethyl acetate- hexanemethanol ( $7: 3: 0.5)$. Valerenic acid was detected by Anisaldehyde- sulphuric acid reagent and the spots were appeared in visible light. Sampling was applied in silica gel plates (60 F 254).

Thin layer chromatography was performed for all of the samples (tablets, caplet; capsules, drop) and valerenic acid standard in three solvent systems.
Calibration Curve: Five different concentrations of valerenic acid were prepared by serial dilution resulting in final concentrations of 0.025 , $0.05,0.1,0.2,0.4 \mathrm{mg} / \mathrm{ml}$. For determination of precision of the method four concentrations of prepared standards were injected duplicate in the same day and in subsequent days.

For determination of accuracy three different concentrations of valerenic acid $(0.05,0.1$, $0.2 \mathrm{mg} / \mathrm{ml}$ ) were injected triplicate and the average of the results were recorded.

Quantitative Analysis: The operating conditions were C-18 reversed phase (VP- ODS $250 \mathrm{x}$ $4.6 \mathrm{~mm}$ ) column, acetonitrile as mobile phase with constant flow rate of $0.8 \mathrm{ml} / \mathrm{min}$ and UV detection at $220 \mathrm{~nm}$.

\section{RESULTS AND DISCUSSION}

Precision and Accuracy: In performance liquid chromatography analysis, the results of repeatability and reproducibility are shown in table 1 and 2 .

The results of accuracy (recovery value) in table 3 which are in acceptable ranges.

Qualitative Analysis: The thin layer chromatography fingerprint shows that all samples contained valerenic acid.

Table 1: The results of repeatability (Intra-day)

\begin{tabular}{ccc}
\hline $\begin{array}{c}\text { Calculated } \\
\text { concentration of } \\
\text { The first injection } \\
(\mathrm{mg} / \mathrm{ml})\end{array}$ & $\begin{array}{c}\text { Calculated concentration } \\
\text { of the second injection } \\
(\mathrm{mg} / \mathrm{ml})\end{array}$ & $R D$ \\
\hline 0.026 & 0.024 & $5.66 \%$ \\
0.098 & 0.096 & $2.99 \%$ \\
0.209 & 0.218 & $2.98 \%$ \\
0.396 & 0.392 & $0.72 \%$ \\
\hline
\end{tabular}

Table 2: The results of repeatability (Inter- day)

\begin{tabular}{ccc}
\hline $\begin{array}{c}\text { Calculated } \\
\begin{array}{c}\text { concentration of } \\
\text { the first time } \\
(\mathrm{mg} / \mathrm{ml})\end{array}\end{array}$ & $\begin{array}{c}\text { Calculated concentration } \\
\text { of the second } \\
\text { time }(\mathrm{mg} / \mathrm{ml})\end{array}$ & $R D$ \\
\hline 0.048 & 0.050 & $2.88 \%$ \\
0.098 & 0.105 & $4.88 \%$ \\
0.209 & 0.212 & $1.01 \%$ \\
0.396 & 0.393 & $0.54 \%$ \\
\hline
\end{tabular}

Table 3: The results of accuracy of method

\begin{tabular}{ccr}
\hline $\begin{array}{c}\text { Expected Concen- } \\
\text { tration }(\mathrm{mg} / \mathrm{ml})\end{array}$ & $\begin{array}{c}\text { Calculated Concen- } \\
\text { tration }(\mathrm{mg} / \mathrm{ml})\end{array}$ & $\begin{array}{c}\text { Recovery } \\
\text { Value }\end{array}$ \\
\hline 0.050 & 0.053 & $99.34 \%$ \\
0.100 & 0.099 & $101.01 \%$ \\
0.200 & 0.213 & $93.90 \%$ \\
\hline
\end{tabular}


In performance liquid chromatography analysis, valerenic acid is clearly observed at 6.7-6.8 minutes.

Valerenic acid was identified by comparing its retention time with the internal standard of valerenic acid. The results of valerenic acid amount of each product analysis are shown in table 4.

Table 4: Calculated amount of valerenic acid in products

\begin{tabular}{|c|c|c|c|}
\hline $\begin{array}{l}\text { Brand name } \\
\text { (manufac- } \\
\text { tured) }\end{array}$ & $\begin{array}{l}\text { Valerenic } \\
\text { acid of } \\
\text { products }(\%)\end{array}$ & \multirow[t]{2}{*}{$\begin{array}{l}\text { Direction } \\
\text { of the } \\
\text { label }\end{array}$} & \multirow[t]{2}{*}{$\begin{array}{l}\text { Calculated } \\
\text { daily dose } \\
\text { of valerenic } \\
\text { acid }(\mathrm{mg})\end{array}$} \\
\hline Futuran & & & \\
\hline $\begin{array}{l}\text { Baldrian } \\
\text { tablet } \\
\text { (Madaus) }\end{array}$ & 0.16 & 3-12/ daily & $0.9-3.6$ \\
\hline Baldrian & & & \\
\hline $\begin{array}{l}\text { Hopfen } \\
\text { tablet } \\
\text { (Twardy) }\end{array}$ & 0.03 & $\begin{array}{l}\text { 1-2/ several } \\
\text { times a day }\end{array}$ & - \\
\hline $\begin{array}{l}\text { Euvegal caplet } \\
\text { (Schwabe) }\end{array}$ & 0.11 & 1- 3 / daily & $0.85-2.55$ \\
\hline $\begin{array}{l}\text { Neurogol tablet } \\
\text { (Goldaru) }\end{array}$ & 0.05 & $\begin{array}{l}1-2 / \text { twice } \\
\text { a day }\end{array}$ & $0.13-0.52$ \\
\hline $\begin{array}{l}\text { Valerian capsule } \\
\text { (Herbi Darou) }\end{array}$ & 0.05 & $\begin{array}{l}1-3 / \text { third } \\
\text { a day }\end{array}$ & $0.5-1.5$ \\
\hline $\begin{array}{l}\text { Antimigrain } \\
\text { Herbal drop } \\
\text { (Goldaru) }\end{array}$ & 3 & $\begin{array}{l}30-40 \text { drop/ } \\
\text { twice a day }\end{array}$ & $0.06-0.024$ \\
\hline
\end{tabular}

Regarding to valerian has many uses in Iranian herb and in other countries, it is used as a sedative widely and considered in industrial filed so valerian products should have efficacy that the consumers use confidently. Valerenic acid is the important active component of valerian and it was concluded that valerenic acid possesses sedative action and is the chemical factor responsible for the sedative effect noted in human clinical trials with aqueous extracts of valerian root (Pizzorno and Murray 1999).

Regarding increased processing temperature favors extraction kinetics, but provokes moderate degradation of valerenic acid (Boyadzhiev et al. 2004) so in this work, valerian products are extracted by maceration method.

Valerenic acid of products is identified by thin layer chromatography method because this method is an easy and economic for identification of effective components. Thin layer chromatography fingerprint shows that all samples contained valerenic acid. The selective solvent system is ethyl acetate- hexane- methanol in ratio $(7: 3: 0.5)$ which separates the spots of components better than other solvent systems.

Valerenic acid of products is determined by performance liquid chromatography method. The selective mobile phase of high performance liquid chromatography method is acetonitrile with flow rate of $0.8 \mathrm{ml} / \mathrm{min}$. This method is easier and more rapid than other systems. Retention time of valerenic acid in this method is 6-7 minutes that it is suitable for determination of active component. For standardization of natural product drugs, single chemical entities," marker compounds" may be used as potency standards in performance Liquid Chromatography analysis (Lazarowych and Pekos 1998).

There is no information about the real amount of active components on the labels in the products which were tested. Powdered valerian should be containing not less than $0.04 \%$ valerenic acid (USP 2004). According to the results, Baldrian Hopfen tablet contains $0.03 \%$ valerenic acid and other samples have not less than $0.04 \%$ valerenic acid. Regarding the suggested direction on the label of these products, the calculated amount of valerenic acid in German valerian products were $0.85-3.6 \mathrm{mg} /$ daily and in Iranian valerian products were $0.13-1.5 \mathrm{mg} /$ daily. This difference is discussible.

\section{ACKNOWLEDGMENT}

The authors are grateful to research council of Shaheed Beheshty University of Medical Sciences (Tehran-Iran) for financial support of this study.

\section{REFERENCES}

Boyadazhiev L, Kancheva D, Gourdan C, Metcheva D 2004. Extraction of valerenic acid from Valerernic (Valerernic officinalis L.) rhizomes. Journal of Pharmazie, 59(9): 727-728.

Integrated Biomolecule Corporation - Product Analysis. Retrieved April 27, 2006, from http://www. purecaps.com/ PDF/ QA/ VL 16.pdf

Lazarowych, NJ, Pekos P 1998. Use of fingerprinting and marker compounds for identification and standardization of botanical drugs: strategies for applying pharmaceutical HPLC analysis to herbal products. Journal of Drug Info, 32: 497- 512.

Mills S, Bone K 2000. Principles and Practice of Phytotherapy, London: Churchill Livingstone, pp 581-584.

Pizzorno JE, Murray MT 1999. Textbook of Natural Medicine, 2nd Edition, London: Churchill Livingstone, Vol (1): 2534.

Shohet, D, Wills RB, Stuart DL 2001. Valepotriates and 
valerenic acid in commercial preparations of valerian available in Australia. Journal of Pharmazie, 56(11): 860- 863 .

Tarrado JJ. 2003. In vitro release of valerenic acid and hyroxyvalerenic acid from valerian tablets. Journal of Pharmazie, 58(9): 636-638

USP 24, NF 19. 2000. United States Pharmacopeial, INC. Patr, 2: 2534. 